\title{
Study on Transformation of University Governance
}

\author{
Yijun Li \\ Henan Provincial Foreign Science \&Technology Exchange Centre \\ Zhengzhou, China, 450003
}

\begin{abstract}
The transformation of the university governance is essentially the restructure of the core institution of the university, involving the interest of many people and great adjustment of power and interest. It has always been the focus of the establishment of modern university institution. Therefore, it is quite necessary to find a typical university as a model to analyze the transformation of university governance for the establishment of modern university institution in China.
\end{abstract}

Keywords-university governance; modern university institution; transformation

\section{INTRODUCTION}

University governance refers to the structure and process of the decision making of the key issue concerned by the related party. The transformation of the university governance is essentially the restructure of the core institution of the university, involving the interest of many people and great adjustment of power and interest. It has always been the focus of the establishment of modern university institution. Therefore, it is quite necessary to find a typical university as a model to analyze the transformation of university governance for the establishment of modern university institution in China. The transformation of university governance in University of Toronto is a typical case for reference. University of Toronto had ever implemented the system of Bi-boards, that is University Board and Academic Board and this kind of University governance model has been very popular in North America and Canada at present. However, The Act of University of Toronto in 1971 established the Uni-board in the University of Toronto. What kind of force behind makes University of Toronto changing from Uni-board to Bi-board? It is worthwhile for us to conduct research about this topic.

\section{THEORETICAL FOUNDATION}

New Institutionalism has done a good job in explaining the transformation of institution of public organizations. New Institutionalism has been widely applied in policy analysis after James March and John Wilson published the paper named as New Institutionalism: Institutional Factors in Political Life. In 1996 Hawl and Taylor published the paper named as "Political Science and Three Schools of New Institution, dividing new institutionalism into three parts: historical institutionalism, rational institutionalism and social institutionalism. At present the Three Schools of New Institution have been very popular in policy analysis and have formed analysis framework with various features.

The basic assumption of rational choice institutionalism is that under the condition of no constraint individual rationality leads to the appearance of collective action dilemma. The most obvious feature of the research paradigm is to analyze political issue by virtue of assumption of rational person, property rights, transaction costs and other basic concepts focusing on rational feature of the political person and the stability of preference. It not only attaches importance to rational calculation of the person, but also attaches importance to achievement of mutual benefits through institutional arrangement. Therefore, rational choice institutionalism gives the explanation of the track of the calculation when it explains the transformation of he institution. This track assumes the exstatus of the institution as the non-government status. The existence of the institution can reduce transaction costs. In their views, the new system and old system are not necessarily having any historical association. As long as there is logic need for institution, the institution can be created. ${ }^{1}$

The basic assumption of historical institutionalism is that conflicts between different interest groups due to scarce resources constitute the core element of the political process. The outstanding feature of this research paradigm is: in the process of the creation and operation, it emphasizes the asymmetry of the power. When the establishment and the development of the institution is analyzed, it emphasizes the track dependence and the political consequences. It proposes comprehensive analysis of the institution and the elements creating a certain political consequences. Therefore, historical institutionalism provides a kind of conflict interpretation in explaining institutional transformation. This track mainly examines the relationship of three variants, namely, old institution, environment and actor. Institution can be created from the conflicts and competition. And it can also be created by the opportunity provided by the transformation of environment.

The basic hypothesis of sociological institutionalism is that: the way the institution impacts the behavior is like follows: the character in a certain process of socialization provides Internalized "code of conduct" and "cognitive template. That is it specifics the actor a certain kind of character under a certain scenario. The main feature of this kind of research paradigm is as follows: institution is specified in the broadest sense. Institution not only includes the formal rules, procedure, and codes, but also includes symbolizing system, cognitive mode and moral template providing significance framework for human behavior. It pointed out the value of cultural authority lies in its providing

${ }^{1}$ Lu Xian Xiang: the Western New Institutional Economics, [M] Chinese Development Press, 2003.56-61 
legitimacy foundation for specific institutional arrangements instead of other institutional arrangements. Therefore, sociological institutionalism provides the interpretation for cultural track in interpreting institutional transformation. According to this interpretation, the birth of new institution is from old institutional culture. It may also be the consequence of the conflicts between old institution and new institution.

The three research tracks of the new institutionalism have their own strengths and they all have limited explanation power in explaining institutional transformation of public organization. Rational choice institutionalism is good at technology analysis in micro field. Sociological institutionalism is good at background exploration in macro field. Historical institutionalism is good at comprehensive interpretation in middle level significance. What is inspiring is that it appears the trend of exchange and integration between different schools. In fact, the three schools already have reached some fundamental consensus. First, the power originated from the institution rather than individual. Second, it puts emphasis on decisive role of structure on political behavior. Third, the regulatory role of institution on behavior is beyond other elements. Institution is not only the consequence of human being's behavior with purpose but also shapes human being's behavior. At present the core assumptions have been revised and the boundary between each other has become increasingly blurred. Therefore, the core assumptions of the three analyses can be integrated into one comprehensive analysis framework. Historical institutionalism itself is a political consequence. Institutional analysis and other factors creating a certain political consequence can be combined to make a comprehensive analysis. This comprehensive analysis framework has very strong explanation power and can provide new analysis perspective for the research of policy transformation in education. Three assumptions are proposed: first, calculation based on limited reasoning is micro foundation of institutional transformation. Second, the power conflict is the dynamic mechanism of institutional transformation. Legitimacy based on cultural identity is one of the decisive factors of institutional transformation. 2 This analysis framework will be applied for the transformation of governance mode of Toronto University.

\section{Historic Review Transformation of Govern Model OF THE UNIVERSITY OF TORONTO}

The University of Toronto is the largest and the most powerful public research university. In history, the transformation of the governance model has demonstrative effect in province of Ontario and even in Canada.

\section{A. Act of University of Toronto in 1906}

An experienced committee was established to conduct a detailed examination of the charter and a proposal was submitted. According to the proposal, the University of Toronto should be appropriately separated from the government and realized university autonomy. A new board should be set up to carry out the autonomy for more effective

${ }^{2}$ B. Guy peters. Institutional Theory in Politics Science. London and New York Wellington Publishing House, 1999. 141-149 university governance. Half of the new members of the board of directors are from outside and are appointed by the government and half are from inside and generated by election. Other than the board, an academic senate composed of experienced senior professors should also be set up to be in charge of academic affairs of the university. This proposal attracted great attention from the Ontario government and was written into the chapter of the University of Toronto and obtained confirmation form the government. And it made great impact on other Canadian universities.

\section{B. Act of University of Toronto in 1971}

The president of the university Bissel proposed that bi-board governance model led to the inefficiency of the management of the university. Uni-board governance institution can get together of the representatives of the different interest group to negotiate. And this proposal is supported by the young staff of the university. In 1971, The provincial agency approved the proposal of Uni-board governance model decided that the Governing Council- the single decision-making institution should be established. And it should be composed of 42 people and most of them should be from outside.

\section{Controversy after the Establishment of Uni-board Governance Model}

After the establishment of Uni-board governance model, a series of executive positions are set up respectively, that is, the school affairs committee, external affairs committee, resources and strategic committee, academic affairs committee. The fewer number of seats for teachers in academic affairs committee is the focus of the controversy. And the struggle for the student to obtain the same number of seats as teachers the teachers last for another decade.

\section{INSTITUTIONAL LOGIC OF TRANSFORMATION OF GOVERNANCE MODEL}

\section{A. Micro Basis}

Micro microcosmic basis of institutional transformation is based on the calculation of the path points Calculating path is to analyze the institutional transformation from the perspective of the actor who makes rational strategic calculation. A certain institution is selected since actors can obtain more benefits than other institutions. If the current institution cannot meet the requirement of obtaining benefit from the trade for the actors, the institution will be transformed. Therefore, transformation is a conscious process. Compared to the model of University Act of 1906, the model of University Act of 1971 made a radical transformation. Under the Act of 1906, Uni-board governance model is adopted. Under the Uni-board governance model, senor administrative management including the president has no power in transforming the internal affairs of the university. This is the micro foundation for President Bissell to extremely promote the governance model of "Uni-board".

\footnotetext{
3 Roger E. Meiners, Tenure and Structure of Higher Education, [J] Journal of Education 2012.43-46
} 


\section{B. Dynamic Mechanism}

Social macro structure shaped institution. Institution ultimately impacted the political output through composing the relationship of political variables. Obviously, the institution is essentially a mid-level structure. On one hand, Macro structure has impact on specific political output through this mid-level structure. On the other hand, the unintended consequences shape the institution and it will have a certain impact on macro social structure. Institutional crisis is usually triggered by external environment and it further lead to the collapse of the old institution. And the inertia triggered political conflicts after shaping the new institution arrangement. Therefore the analysis of intuitional transformation can be transferred into the exploration of political contrast between and among different parties under a certain university regime. In the transformation of the governance model of University of Toronto, university institution as the mid-level structure include two aspects, one is the relationship between government and university and the other is the relationship between internal groups.

Since 1849, the university of Toronto escaped from the control of the church. Games of between government and university have been on. At the beginning of 20th Century, the contrast led to the establishment of Royal Flavelle Council that is in charge of the relationship between government and university and arrangement of the university governance structure. In 1906, the report of the Council established a new model set up a new university governance model that is on the basis of core concept of the moderate separation of internal administration power of the university and the direct political power of the government. The separation can be realized by the board of directors of the university authorized by government. It formed the connectional foundation of the Act of University of Toronto. The core established the governance model of "Bi-board". Under this government model, corporate board made up of amateurs is in charge of administrative affairs. Academic senate made up of president, professors, representative of administrative officials from the university is in charge of academic affairs. Government seldom interferes with the internal policy resolution of the university. As far as the internal relationship of the groups, there are power games between president, professors, teachers, administrative officers and students.

\section{Macro Background}

The macro background of the institutional transformation is cultural path. Legitimacy is the core of the cultural path and the legitimacy of the institution in the future is intensified by cultural interpretation. From the perspective of the sociological institutions, institutional framework is a very tight cultural belief system. And of the purpose and behavior can be interpreted from two aspects, on one hand, the actor has to make choice between the cost and benefit embedded in the institutional environment. On the other hand, the choice of the actor is restricted by the cultural heritage of the society such as the culture, fairy tales and the consciousness status. If the actor is taken as the university organization, university

\footnotetext{
${ }^{4}$ Martin L. Friedland. The History of University of Toronto.2008. [M] University of Toronto Press,78-86
}

organization will comply with all kinds of institutionalized fairy tales to promote the justice and steadiness. The legitimacy based on the cultural identity is a decisive factor of the transformation of governance model of university. Cultural interpretation is the important means of enhancing the legitimacy of the system in the future. The most powerful of cultural interpretation of the transformation of governance model of University of Toronto is democracy. The transformation of governance model of university is restricted by the macro social structure. It has the same structural nature as the social macro institution. Meanwhile, transformation cannot deviate from the internal logic of the university. It cannot deviate too far away from the traditional university concept. Otherwise, it will also face the crisis of identity.

\section{CONCLUSIONS AND IMPLICATIONS}

Three analysis paths in the interpretation of the new institutionalism can be integrated into one comprehensive analytical framework due to their acknowledgement of limited rationality of actor, dependence of institutional transformation and important role of culture opinion. The difference is that they are in different positions in the three analysis paths. The case study of the transformation of governance model of university completely demonstrated the explanation power of the analysis framework.

\section{A. Micro Foundation}

The opportunity of obtaining profit is the micro foundation for the transformation of governance model of university. The fundamental institutional transformation is because the innovative design can bring out great potential benefits for the governor of Ontario and the president, although the actual situation is not like what they expected.

\section{B. Dynamic Mechanism}

The transformation of the governance pattern is the complicated games procedures of the participants such as the government, the society, the board of directors, the president, the administrative officers, the teachers and the students. And contrast of the power plays an important role in institutional transformation. The sudden transformation of relationship of government and the university stimulated the institutional crisis of the university. Games of the contrasting parties successfully shaped the new institutions. It stimulates the transformation of bi-board system to Uni--board system of the University of Toronto.

\section{Macro Background}

The macro background of the institutional transformation is cultural path. The legitimacy based on the cultural identity is a decisive factor of the transformation of governance model of university. Cultural interpretation is the important means of enhancing the legitimacy of the system in the future. The most powerful of cultural interpretation of the transformation of governance model of University of Toronto is democracy. The transformation of governance model of university is restricted by the macro social structure. It has the same structural nature as the social macro institution. Meanwhile, transformation

\footnotetext{
${ }^{5}$ Hawl. Political Science and Three New Institutionalisms. [J] Comparison of the Economic and Social System. 2011.5,31-36.
} 
cannot deviate from the internal logic of the university. It can not deviate too far away from the traditional university concept. Otherwise, it will also face the crisis of identity. ${ }^{6}$

In a word, the primary dynamic for is rational calculation. The institutional transformation of the force is a rational calculation and actor expected new transformation would bring benefits for himself. Due to the limited rationality of the actor, unexpected consequences may take place in institutional transformation. Games often conducted under a certain social structure. Political conflicts provide unlimited dynamic for institutional transformation. Under the pressure of the legitimacy, the path of transformation is limited and it demonstrated connection in a certain degree between the old institution and the new institution.

\section{ACKNOWLEDGEMENTS}

This research paper is under the International Cooperation Project of Henan Provincial Science and Technology Bureau: Study on Tax Loss of Sino-foreign Cooperated University; Number of the project: 134300510042.

\section{REFERENCES}

[1] Lu Xian Xiang: the Western New Institutional Economics, [M] Chinese Development Press, 2003.56-61

[2] B. Guy peters. Institutional Theory in Politics Science. London and New York Wellington House, 1999; 141-149

[3] Roger E. Meiners, Tenure and Structure of Higher Education, [J]Journal of Education 2012.43-46

[4] Martin L. Friedland. The History of University of Toronto., [M] University of Toronto Press.2008,78-86

[5] Hawl. Political Science and Three New Institutionalisms. [J] Comparison of the Economic and Social System. 2011.5,31-36.

[6] He Junzhi: A Structural History and Behavior - Collection of Historical Institutionalism in Political Science[M]. Fudan University Press, $2009,82-86$

\footnotetext{
${ }^{6}$ He Junzhi: A Structural History and Behavior - Collection of Historical Institutionalism in Political Science. Fudan University Press, 2009,82-86.
} 